\title{
Covid-19: The Wuhan Pandemic
}

Tooba Masood

\section{ABSTRACT:}

Coronavirus belongs to a large family of viruses that usually cause respiratory illness in human beings that can be mild and severe depending upon the strain. In 2002, the outbreak of SARS (severe acute respiratory syndrome) reported more than 8000 infected cases with 774 mortalities. In 2012, the outbreak of MERS (middle east respiratory syndrome) infected around 2494 people and 858 deaths were reported according to the WHO. In January 2020, a new strain of coronavirus named 2019-nCoV has been identified in China. The number of confirmed cases has been increasing reaching 5,593,631 cases worldwide with 353,334 deaths up till $28^{\text {th }}$ May 2020 according to WHO situation report-129. Concerned authorities are working on minimizing its spread. Prevention guidelines have been released by WHO, hoping to control the transmission and save the world from the effects of this novel virus.

$\overline{\text { How }}$ to cite this Article:

Masood T. Covid-19: The Wuhan Pandemic. J Bahria Uni Med Dental Coll. 2020;10(3): 251-3 DOI: https://doi.org/ 10.51985/ JBUMDC2020009

\section{INTRODUCTION:}

Coronaviruses are a large group of viruses named for the crown-like spikes on their surface. There are four main subgroupings of coronaviruses, known as alpha, beta, gamma, and delta. The identification of human coronavirus was first seen in the mid-1960s. The coronaviruses that are common and can infect people include 229E, NL63, OC43, HKU1. Other human coronaviruses are MERS-CoV (causes Middle East Respiratory Syndrome), SARS-CoV (causes Severe Acute Respiratory Syndrome) and 2019 Novel Coronavirus (2019-nCoV) that has been recently identified in China. ${ }^{1}$

\section{OUTBREAK OF NOVEL CORONAVIRUS (2019- nCoV):}

On $31^{\text {st }}$ December 2019, WHO was informed about the growing cases of pneumonia in Wuhan City, Hubei Province of China. The causative agent was not identified till $7^{\text {th }}$ January 2020 when Chinese authorities isolated and confirmed the virus which was identified to be a Coronavirus and named as Novel Coronavirus "2019- nCov" because it's a new strain that was previously not identified in humans. Later, WHO renamed it to SARS-CoV-2 to relate it to the disease symptomatology. On 12 January 2020, China shared the genetic sequence of the novel coronavirus for countries to use in developing specific diagnostic kits.

It was suspected that the outbreak of this virus was initially associated with the exposure in one seafood market in Wuhan. The exact host was not identified then but, its spread has thought to be viral from the improper handling of animals which is further transmitting among humans. ${ }^{2}$ Later, the origin of the SARS-CoV-2 genome has been linked to bats akin to the SARS-CoV-1 and MERS-CoV viruses. ${ }^{3}$

Г - - - - - - - - - - - - ᄀ

Tooba Masood

Lecturer, Department of Physiology

I Bahria University Medical and Dental College, Karachi

| Email: toobamasood@live.com

I Received: 29-Jan-2020

Accepted: 25-Jun-2020
After SARS and MERS outbreak in the past, SARS-CoV2 is the third coronavirus to emerge in the human population in the past two decades - an emergence that has put global public health institutions on high alert. ${ }^{4}$

The number of lab-confirmed cases of Coronavirus is increasing since then and reaches beyond the border of China involving 213 countries and territories around the world. The statistics about the number of confirmed cases globally by $28^{\text {th }}$ May 2020 reported by WHO situation report129 is given below in the table. ${ }^{5}$

\section{VIROLOGY:}

SARS-CoV2 is from the beta Coronavirus family, singlestranded RNA, enveloped virus about 50-200 nm in diameter. It contains an encoded structural protein called Spike Glycoprotein (S) that bind to angiotensin-converting enzyme 2 (ACE2) receptor on type II pneumocyte. The entry of SARS-CoV-2 into the type II pneumocyte is via endocytosis and then multiplies in the cytoplasm further leading to apoptosis. The RNA from the SARS-CoV-2 will be recognized by the pattern recognition receptor or toll-like receptors leading to a chemokine surge which causes neutrophil migration and activation. This causes the destruction of the alveolar-capillary walls and fluid leaks into the alveolar sacs. ${ }^{6}$

\section{MODE OF TRANSMISSION:}

COVID-19 is thought to be transmitted from improper handling of animals to humans and further spreading to other humans directly or indirectly.

Direct transmission to other person can be through respiratory droplets ( $>5-10 \mathrm{~mm}$ in diameter) and can easily infect others in close contact of 1 meter distance when the infected person cough or sneeze.

Indirect transmission can be through touching the surfaces or objects in the immediate environment of an infected individual and touching either their mouth, nose or eyes without washing hands properly. 
Situation in numbers (by WHO Region)

Total (new cases in last 24 hours)

\begin{tabular}{|l|l|l|}
\hline Globally & $5,593,631$ cases $(104505)$ & 353,334 deaths $(4221)$ \\
\hline Africa & 89,592 cases $(3777)$ & 2370 deaths $(62)$ \\
\hline Americas & $2,556,479$ cases $(60,254)$ & 148,412 deaths $(2584)$ \\
\hline Eastern Mediterranean & 461,824 cases $(12,234)$ & 11,621 deaths $(169)$ \\
\hline Europe & $2,079,924$ cases $(18,096)$ & 177,331 deaths $(1105)$ \\
\hline South-East Asia & 227,611 cases $(9088)$ & 6630 deaths $(271)$ \\
\hline Western Pacific & 177,460 cases $(1056)$ & 6957 deaths $(30)$ \\
\hline
\end{tabular}

Airborne transmission may be possible in specific circumstances and settings in which procedures or support treatments that generate aerosols are performed; i.e., endotracheal intubation, bronchoscopy, open suctioning, manual ventilation before intubation, tracheostomy, and cardiopulmonary resuscitation etc. ${ }^{7}$

\section{SYMPTOMS:}

Symptoms may appear in 2-14 days after exposure to the virus and include:

Fever, cough, sore throat, dyspnea, runny nose, muscle pain, headache, malaise, new loss of taste and smell, nausea and vomiting. If the infection spreads into the lower respiratory tract it can develop pneumonia, sepsis and can lead to death. ${ }^{8}$

\section{SUSCEPTIBILITY OF INFECTION:}

Patients with heart disease, weak immunity, infants or older adults $>60$ years of age are more prone to get this infection. ${ }^{9}$

\section{INVESTIGATIONS AND DIAGNOSIS:}

As the coronavirus causes respiratory illness, the laboratory tests are done on respiratory specimens (nasopharyngeal swabs, sputum etc) and serum used to detect human coronavirus. Its been reported that the previous outbreak of SARS and MERS were also confirmed by reversetranscriptase polymerase chain reaction (RT-PCR). So, SARS-CoV-2 is also reported to be diagnosed by the genetic code sequencing via RT-PCV. ${ }^{10}$ Although the sensitivity of PCR is around 66-80\% which is one of the reasons of having false negative results.

In one of the largest research carried out in China showed CT-chest had a 95\% sensitivity in making an early diagnosis of COVID-19 through the identification of ground-glass opacities. But it has some cons including huge economic burden on the healthcare resources and the potential to contaminate the CT scanners. ${ }^{11}$

\section{PREVENTION:}

There is no vaccine available for SARS-CoV-2. Following three steps altogether will help prevent the spread of COVID19.

1. Social distancing.

2. Hand washing.

3. Wearing mask.
Social distancing will help keep a healthy person less prone to get infection.

Washing hands with soap and water and using alcohol-based sanitizer will further add protection against this disease.

Wearing mask will keep an infected person from spreading the virus to healthy individual and also helps in keeping your hands away from touching your face (indirect route of infection).

Using a disinfectant to clean the frequently used objects by the infected individuals will add sugar on top. ${ }^{12}$

\section{TREATMENT:}

There is no specific antiviral treatment or vaccine for this new strain virus. In mild cases, only supportive care can help relieve symptoms i.e; resting, adequate hydration, gargling and the use of antipyretics. ${ }^{13}$ In severe cases, use of supplemental oxygen at $5 \mathrm{~L} / \mathrm{min}$ and $\mathrm{SaO} 2$ of $>90 \%$ should be maintained. According to the WHO situation report-129, the use of antibiotics for treatment of acute coinfection in mild to moderate COVID-19 cases has not been recommended. Antivirals including interferon $\alpha$ (IFN- $\alpha$ ), lopinavir/ritonavir, chloroquine phosphate, ribavirin, arbidol, favipiravir, remdesivir and darunavir should not be administered as treatment of COVID-19 outside the context of clinical trial. In hospitalized patients, prophylactic administration of heparin according to local and international standards to prevent venous thromboembolism can be helpful.

Hoping to have an effective drug or vaccine against this new virus soon. ${ }^{14}$

SCHOOL'S OUT, BUT CLASS'S ON: ROLE OF SOCIAL DISTANCING IN EDUCATIONAL INSTITUTES

As it has been cleared from all the guidelines provided by the WHO and CDC, that maintaining social distance and staying at home will keep a person at a very low risk of attaining the COVID-19. COVID-19 has become a challenge for the education system as well, affecting all the students globally. In order to prevent the spread of disease rapidly, government has decided to keep the institutes closed till further notice depending upon the country's situation. To contain this virus from further spreading we mainly need to avoid gatherings and completely follow social distancing. 
To keep students at a low risk, we can't gather them in such large numbers in their educational institutions. Hence, online education has become trendy these days to overcome the academic loss of students due to this pandemic. If education can be gained online sitting at home in safe environment then it should be promoted atleast till things fall into place. ${ }^{15}$

\section{CONCLUSION:}

Coronavirus is a large family virus whose outbreak as SARS and MERS caused an increased mortality rate in less time span. The new strain identified recently in January 2020 is spreading throughout the world. Looking at the statistics update, the number of infected cases and deaths is continuously increasing. It is crucial to minimize its spread and find the cure as soon as possible otherwise we will see an abnormally increased number in statistics of these cases which can affect the world badly.

- - - - - - - - - - - - - - ר

| Author Contribution:

| Tooba Masood: Selection of Topic, writing abstract, introduction, history, mode of transmission, signs and symptoms, investigations \& diagnosis, prevention, treatment \& conclusion.

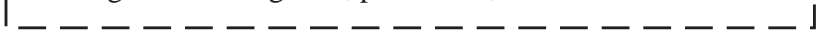

\section{REFERENCES:}

1) Centers for Disease Control and Prevention, CDC, (https:// www.cdc.gov/coronavirus/types.html)

2) Novel Coronavirus (2019-nCoV) situation report-1, World Health Organization, (https://www.who.int/ emergencies/ diseases/ novel-coronavirus-2019/situation-reports)

3) Bats are natural reservoirs of SARS-like coronaviruses. Li W, Shi Z, Yu M, Ren W, Smith C, Epstein JH, Wang H, Crameri G, Hu Z, Zhang H, Zhang J, McEachern J, Field H, Daszak P, Eaton BT, Zhang S, Wang LF Science. 2005 Oct 28; 310(5748):676-9. [PubMed] [Ref list]

4) Vincent J. Munster, Ph.D., Marion Koopmans, D.V.M., Neeltje van Doremalen, Ph.D., Debby van Riel, Ph.D., and Emmie de Wit, Ph.D. A Novel Coronavirus Emerging in China Key Questions for Impact Assessment, The New England Journal of Medicine (https://www.nejm. org/doi/full/ 10.1056 /NEJMp2000929)
5) Novel Coronavirus (2019-nCoV) situation report-129, World Health Organization, (https://www. who.int/ emergencies/ diseases/novel-coronavirus-2019/situation-reports)

6) A Comprehensive Literature Review on the Clinical Presentation, and Management of the Pandemic Coronavirus Disease 2019 (COVID-19). Monitoring Editor: Alexander Muacevic and John R Adler Pramath Kakodkar, 1 Nagham Kaka,1 and MN Baig2(https://www.ncbi. nlm.nih.gov/ pmc/articles/PMC7138423/)

7) Modes of transmission of virus causing COVID-19: implications for IPC precaution recommendations. (https:// www. who.int/news-room/commentaries/detail/modes-oftransmission-of-virus-causing-covid-19-implications-for-ipcprecaution-recommendations )

8) Centers for Disease Control and Prevention, CDC, Symptoms of Coronavirus. (https://www.cdc.gov/coronavirus/2019ncov/symptoms-testing/symptoms.html)

9) Symptoms of Coronavirus, WebMD, (https://www. webmd.com /lung/coronavirus\#2)

10) Laboratory testing for 2019 novel coronavirus (2019-nCoV)in suspected human cases, Interim guidance 14 January 2020, World Health Organization, (https://www.who.int/docs/defaultsource/coronaviruse/20200114-interim-laboratory-guidanceversion.pdf?sfvrsn=6967c39b_4\&download=true)

11) A Comprehensive Literature Review on the Clinical Presentation, and Management of the Pandemic Coronavirus Disease 2019 (COVID-19) (https://www. ncbi.nlm. nih. gov/ pmc/articles/PMC7138423/)

12) Centers for Disease Control and Prevention, CDC, Prevention of Coronavirus. (https://www.cdc.gov/ coronavirus/ mers /about/prevention.html)

13) What to do about Coronavirus, WebMD, (https:// www. webmd.com/lung/coronavirus\#2)

14) Discovering Drugs to Treat Coronavirus Disease 2019 (COVID-19) Liying Dong 1 , Shasha Hu 2 , Jianjun Gao 1 (https://pubmed.ncbi.nlm.nih.gov/32147628/)

15) Centers for Disease Control and Prevention, CDC, Considerations for Institutes of Higher Education. (https://www.cdc.gov/coronavirus/2019-ncov/ community /colleges-universities/considerations.html) 